\title{
Cystic fibrosis
}

\author{
MARGARET E. HODSON \\ M.D., M.Sc., F.R.C.P., D.A.
}

Cardiothoracic Institute and Brompton Hospital, Fulham Road, London SW3 6HP

\section{Introduction}

Cystic fibrosis (CF) is a disease characterized by chronic bronchopulmonary infection, malabsorption and a high sweat sodium concentration. Fanconi, Uehlinger and Knauer in 1936 recorded cases with congenital pancreatic disease and bronchiectasis, but the first clinical and pathological description of the disease was by Andersen in 1938. At that time $80 \%$ of babies born with this condition died within 1 year of birth, but now many patients are surviving into adult life. In the United Kingdom, the Brompton Hospital currently cares for over 200 CF patients over 16 years of age, the oldest being 50 years.

Possible reasons for this improved survival are earlier diagnosis, better paediatric care, diagnosis of milder cases, improved techniques of physiotherapy and the advent of antibiotics.

There are many reviews of the rapidly growing basic research into CF (di Sant 'Agnese and Davis, 1976; Wood, Boat and Doershuk, 1976; Williamson, Crampton and Clarke, 1983). This article will therefore concentrate on the clinical aspects of the disease and particularly the management of the older patient.

\section{Genetics}

The basic defect in $\mathrm{CF}$ is unknown. The condition occurs in Caucasian, black and Mongoloid races but is most common among Caucasians. In Caucasians the incidence of the disease is 1:2,000 live births. The carrier frequency is $1: 20-1: 25$ and 1 in 500 marriages will be between two heterozygotes. These individuals will be completely asymptomatic and have no reason to know they carry the gene until they produce an affected child. It is commonly stated there must be a heterozygote advantage to account for the high incidence of the CF gene in the population but no such advantage has been identified. The disease is inherited as an autosomal recessive. There is therefore a 1:4 chance of each pregnancy producing a CF child when both parents are carriers of the gene.
Much work has been done on antenatal diagnosis based mainly on protease activity in the amniotic fluid (Rao, Platt and Nadler 1978; Brock and Hayward, 1979; Nadler, Rembelski and Mesirow, 1981). There is at present no accurate test available. Many parents having had one CF child find a 25\% risk of another affected child unacceptable. In this situation skilled counselling and contraceptive advice are essential.

Skilled genetic counselling is also essential for the healthy siblings and other relatives of the CF patient, many of whom may over-estimate their chances of having an affected child. The empiric risks of having a CF child by a relative of a CF patient are discussed in detail by Raeburn (1983). If an accurate test of CF carriers was available it could be used to identify those siblings of a $\mathrm{CF}$ patient who were carriers. If necessary, their spouse could also be tested. Intensive research has also been undertaken into carrier detection (Wilson and Fundenberg, 1978; Wilson, 1980 ) but at the time of writing no reliable test is available.

\section{Presentation}

Patients with CF may present (10\%) with meconium ileus within $24 \mathrm{hr}$ of birth. This is a condition in which the baby has intestinal obstruction due to the high protein content of the meconium in the small bowel. Surgical intervention is usually necessary. Other common methods of presentation are respiratory tract infections, malabsorption or failure to thrive. The majority of patients are diagnosed within 1 year of birth.

Other modes of presentation during childhood include volvulus, intussusception, rectal prolapse, jaundice, hypo-proteinaemia, hypo-prothrombinaemia, metabolic alkalosis and electrolyte imbalance. Mothers may notice the baby has a 'salty taste' when kissed. Older patients may present with nasal polyps, sinusitis, pancreatitis, abdominal masses, 'meconium ileus equivalent', hepatosplenomegaly, haemoptysis, pneumothorax, finger clubbing, hypertrophic pul- 
monary osteoarthropathy, cor pulmonale, diabetes mellitus, delayed puberty and azospermia in males.

Most patients in whom the diagnosis is delayed into adolescence or adult life are those with pulmonary symptoms and no malabsorption $(10-20 \%$ of patients). These individuals are often erroneously labelled as having bronchitis, bronchiectasis or asthma. It is important to remember that there is a wide spectrum of disease and not all patients look ill and severely malnourished.

\section{Diagnosis}

The diagnosis of CF depends upon careful history and examination, bearing in mind the features mentioned above, together with confirmatory tests. The most important diagnostic test for $\mathrm{CF}$ is the sweat test (di Sant 'Agnese and Davis, 1953; McKendrick, 1962). Shwachman, Mahmoodian and Neff (1981) studied the sweat sodium concentrations in 252 CF patients and controls. The mean sweat sodium for CF patients was $111.1 \mathrm{mmol} / 1$, and for the controls $28.1 \mathrm{mmol} / 1$. Children with $\mathrm{CF}$ had a range of values for sodium, $60-140 \mathrm{mmol} / 1$. Most paediatric centres would regard two sweat sodiums of over $70 \mathrm{mmol} / 1$ as diagnostic, and over $60 \mathrm{mmol} / 1$ as suspicious. There is some evidence that normal adults have a higher sweat sodium than normal children. Therefore the diagnosis of CF in an older patient must never be made unless two sweat sodiums are over $70 \mathrm{mmol} / \mathrm{l}$. Modifications of the sweat test using fluorohydrocortisone may be useful in the diagnosis of the older patient (Hodson et al., 1983).

The sweat test. Most methods are based upon use of pilocarpine iontophoresis as described by Gibson and Cooke (1959). The pilocarpine penetration of the skin is enhanced by a small galvanic current and this causes optimum stimulation of the sweat glands. At least $100 \mathrm{mg}$ of sweat is essential for accurate results. When performed by an experienced technician in a centre which is regularly performing sweat tests, this is a very accurate diagnostic test. Attention to detail is important and this is discussed fully by Kuzemko and Heeley (1983).

Tests of pancreatic dysfunction. These are rarely needed to diagnose CF. However, in cases where the diagnosis is in doubt measurement of pancreatic enzymes following duodenal intubation should be performed. Direct stimulation of the pancreas by a pancreozymin-secretin test in the majority of patients with $C F$ demonstrates reduction in the volume and bicarbonate content of pancreatic enzymes even in those patients without malabsorption (Dreiling and Janowitz, 1962). Another indirect test of pancreatic function is the PABA test (Sacher, Kobsa and Shmerling, 1978).
Screening tests. These tests of the newborn have been employed in the assumption that the earlie treatment is started the better the prognosis for the individual child. Tests such as the palm test, mecon:ium albumin test, meconium lactase activity, an faecal trypsin assays have been used. None of these have proved to be satisfactory. Blood immunoreac tive trypsin (IRT) levels are currently under investi gation as a screening test for CF. It is known that th serum IRT is raised in infants with CF (Crossley Elliott and Smith, 1979) although it drops to very low levels in adults with CF (Dandona et al., 1979). A few drops of blood collected on paper and dried haves been used to estimate the IRT in newborn infants. $\overrightarrow{\text { fw }}$ large prospective trial using this technique in oves 20,000 infants, aged 1-2 weeks, is in progres? (Kuzemko and Heeley, 1983).

\section{The respiratory system}

\section{Pathology}

CF effects most organs in the body, but it is the् severity of the bronchopulmonary disease that detero mines morbidity and mortality. The lungs in CF are structurally normal at birth, but are subject to recurrent infection and chronic mucus hypersecres tion. Bronchitis and bronchiolitis are commonly found at autopsy in patients more than one mont age (Bedrossian et al., 1976). Chronic inflammatron causes bronchiolar scarring and stenosis leadingotito distal hyperinflation and collapse. Goblet cell metas plasia is usually striking. There is no convincing evidence of ciliary abnormalities in the respiratorg tract. Mucus hypersecretion causes areas of brong chiectasis which are usually widespread in olde patients, and small areas of consolidation develop. A? pulmonary disease progresses, ventilation perfusion imbalance occurs leading to hypoxia. Bronchia arteries become hypertrophied and later in the disease cor pulmonale may develop. In older patients with severe disease, pneumothorax and massive pulmonary haemorrhage may complicate alread severe pulmonary disease. The changes in the lungi are summarized in Table 1.

\section{Physiology}

Early in the disease, abnormalities which probab indicate changes in the small airways may be detected. These include a change in the slope of phase 3 of the closing volume curve, changes in $\mathrm{V}_{\text {Iso }} \dot{\mathrm{D}}$ using air and helium oxygen mixtures, reduced $P_{\mathrm{AO}}$ increased physiological dead space and residuat volume/total lung capacity (RV/TLC) ratios and aß abnormal flow volume curve. With increasing diseas an increase in airways resistance, a decrease in force expiratory volume $\left(F_{E V}\right)$, forced vital capacity (FVC), peak expiratory flow rate (PEFR), togetheo 
TABLE 1. Pulmonary disease in cystic fibrosis

\begin{tabular}{lll}
\hline & Early lesions & Late complications \\
\hline Tendency to infection & $\begin{array}{l}\text { Mucous plugs } \\
\text { Bronchitis } \\
\text { Bronchiolitis } \\
\text { Pneumonia } \\
\text { Collapse } \\
\text { Bronchiectasis }\end{array}$ & Cor pulmonale \\
$\begin{array}{l}\text { Tendency to mucus } \\
\text { hypersecretion }\end{array}$ & $\begin{array}{l}\text { Severe haemoptysis } \\
\text { Allergic } \\
\text { bronchopulmonary } \\
\text { aspergillosis } \\
\text { Cardio-respiratory } \\
\text { failure }\end{array}$ \\
\hline
\end{tabular}

with an increase in anatomical dead space and a rising $\mathrm{PACO}_{2}$ occur. These changes have been discussed in detail by Levison and Tabachnik (1983). For practical purposes, to monitor the progress of a patient simple tests available in any clinic such as PEFR, FEV, and FVC are adequate.

\section{Immunology}

CF patients are highly susceptible to respiratory tract infections but they are surprisingly resistant to infection elsewhere. Bacteraemia is very unusual (McCarthy, Rourk and Spock, 1980) and so is amyloidosis (Prior and Crawford, 1980). The possibility of an immunological defect, especially localized to the respiratory tree, is attractive. Many studies have shown raised levels of serum immunoglobulins in CF (Hodson, 1980), although Matthews et al. (1980) showed low levels of immunoglobulins in children with mild pulmonary disease. Local immunoglobulin production within the respiratory tree appears normal and antibody production to infecting bacteria is also normal. There is indeed evidence of overactivity of the immune system. Atopy has been reported as ranging from 10-88\% (Hodson and Warner, 1983) and several workers have reported high levels of IgE (Wallwork et al., 1974). Fifty per cent of patients have a positive immediate skin test reaction to Aspergillus fumigatus (Warren et al., 1975) and $31 \%$ of patients have precipitins to $A$. fumigatus (Mearns, Longbottom and Batten, 1967).

There is evidence of tissue (McFarlane et al., 1975) and circulating (Beldon, Hodson and Batten, 1980) immune complexes in CF. There is also evidence of excess autoantibody production to smooth muscle (Hodson and Turner-Warwick, 1981). No specific abnormality of complement or the T-cell system has been confirmed. There is to date no evidence of an immune defect in $\mathrm{CF}$, but further work on the immune system within the lung is now feasible using the fibreoptic bronchoscope and lung lavage techniques.

\section{Pulmonary pathogens}

The bacteria most commonly isolated from the pulmonary tree in CF are Staphylococcus aureus, Pseudomonas aeruginosa, and Haemophilus influenzae. In childhood, $S$. aureus used to be the most common pathogen, but in recent years $P$. aeruginosa has become more common. In the adolescent and adult population, $P$. aeruginosa is the most commonly isolated organism. In a recent series reported from the Brompton Hospital, $66 \%$ of patients were chronically infected with $P$. aeruginosa (Batten, 1983a). Other bacteria which may be isolated from the patient's sputum include Klebsiella pneumoniae, Streptococcus pneumoniae, Mycobacterium tuberculosis, anaerobic bacteria and atypical mycobacteria. Recently interest has arisen in the possible role of infection due to Legionella pneumophila (Efthimiou et al., 1984). Viruses may be an important trigger for acute episodes of pulmonary infection; respiratory syncytial virus, influenza, para-influenza and rhinoviruses may all be important. Some patients may become infected with Mycoplasma pneumoniae or Chlamydia.

\section{Clinical features}

The symptoms experienced by the patient will depend upon the degree of severity of the disease. Some patients may have minimal symptoms, others will have cough and sputum. In older patients, haemoptysis may occur. Patients may be breathless on exertion or even at rest. Chest pain can occur following over-vigorous physiotherapy or in association with a pneumothorax. Some patients wheeze. The physical signs likewise depend on the extent of the disease. Many patients, even with mild symptoms, have finger clubbing. In early disease the only abnormal observations may be crepitations or crackles over areas of retained secretion or scattered rhonchi. As the disease progresses, cyanosis, tachypnoea, intercostal indrawing, overinflation and pigeon chest deformities may occur.

\section{Radiology}

The chest radiography is usually normal at birth and the earliest changes are thickening of the bronchial walls, particularly in the upper zones. As the disease progresses overinflation of the lungs may occur with low diaphragms and ill-defined nodular shadows $2-5 \mathrm{~mm}$ in size appear (Fig. 1). These may be transient or persistent. Scattered atelectasis or lobar collapse may occur and in advanced disease the pulmonary artery shadows may be prominent.

\section{Treatment}

Prevention of pulmonary infection. CF children 
should be encouraged to live as normal a life as possible but efforts should be made, especially during the first 2 years of life, to avoid exposing them to others with respiratory tract infections. Children with CF should be given immunization against pertussis and measles as well as other routine inoculations. Influenza vaccine is also probably of benefit, especially when an epidemic threatens. Trials of $P$. aeruginosa vaccine have been undertaken but as yet have shown no benefit.

Antimicrobial drugs. Infection due to $S$. aureus should be treated with adequate doses of flucloxacillin or erythromycin. Fucidic acid can be used in addition in severe infection. When the infecting pathogen is $H$. influenzae amoxycillin, tetracycline, oral cephalosporins, co-trimoxazole, or erythromycin may be used. In severely sick patients, chloramphenicol can be very effective. Amoxycillin with clavulanic acid (Augmentin) may have a limited role in the treatment of infection with $H$. influenzae where betalactamases are also present in the sputum. Some beta-lactamases can be inhibited by the clavulanic acid.

There is currently no suitable oral agent active against $P$. aeruginosa. Patients chronically infected with this pathogen are treated with intravenous chemotherapy when there is evidence of an acute deterioration, such as increasing cough, sputum or breathlessness, together with a deterioration in the chest radiograph or PEFR, FEV 1 or FVC. The patients are treated for 10-14 days using an aminoglycoside, such as gentamicin, tobramycin or netilmicin, together with an anti-pseudomonal penicillin or cephalosporin. Suitable companion drugs for the aminoglycoside are carbenicillin, ticarcillin, azlocillin or ceftazidime. There is no evidence from clinical studies of the superiority of one or other of these penicillins. Penketh, Hodson and Batten (1982b) compared ticarcillin with carbenicillin and were unable to show any difference in clinical response. A comparison of azlocillin with carbenicillin and tobramycin with gentamicin showed no difference in clinical response with any of the regimens used (Hodson and Batten, 1981; Hodson, Wingfield and Batten, 1983). Piperacillin is best avoided in the treatment of CF patients as a number of febrile reactions have been seen following the use of this drug. It is essential that the level of aminoglycoside is monitored by proper peak and trough levels. The levels of gentamicin should be $8-10 \mu \mathrm{g} / \mathrm{ml} 15 \mathrm{~min}$ after intravenous injection. Side effects from these agents are uncommon. Most patients given this treatment will, after 10 or 14 days, feel better, have a reduction in sputum volume and an improvement in PEFR, FEV 1 and FVC in some cases by as much as $40 \%$. A double-blind, randomized, crossover trial of aerosol gentamicin and carbenicillin (Hodson, Pen- keth and Batten, 1981) demonstrated subjective an objective benefit in young adults chronically infecte with Pseudomonas aeruginosa. The patients were given $1 \mathrm{~g}$ of carbenicillin and $80 \mathrm{mg}$ of gentamicin,. twice daily, administered by a Bird nebulizer drive震 by an air compressor. There was a reduction in the number of admissions to hospital for intravenous: therapy when the patients were taking the active preparation. The indications for aerosol antibiotics i the management of chronic pseudomonas infection in CF have not yet been established. It is tedious? time-consuming and expensive. Currently the authof only gives it to patients requiring frequent hospitat admissions, or those whose condition is relentlessl $\overrightarrow{\text { w }}$ declining. Many of these patients have improveg when using twice daily aerosol antibiotics.

Physiotherapy. This is perhaps the most important. element of the respiratory care programme. From the time of diagnosis the parents should be taughis postural drainage and chest physiotherapy. All patients with CF should have a period of physiotherap $\mathrm{N}$ twice daily. If there is no sputum, the period of treatment can be very short, but if there is sputum? production, formal physiotherapy should be per $\overrightarrow{\bar{r}}$ formed at least twice daily. This should be increase to four times daily during acute exacerbations an respiratory infections. Various modes of physiotherapy are used, such as postural drainage, manfiab percussion, vibration, coughing and forced exp年 $a^{ \pm}$ tion (Hodson and Gaskell, 1983). For post drainage the patient may be tipped over a pillow of foam wedge; a small tipping bed is also available (Fig. 2). Older patients should be taught to perforrif their own physiotherapy using the forced expiration technique (FET) (Pryor et al., 1979). FET is a huff combined with periods of relaxation and controlles breathing. To produce an effective huff the patient takes a medium breath in and breathes out forcibl through the mouth contracting the muscles of the abdomen. One or two huffs from mid-lung volume te low-lung volume are followed by controlled breathoing. Huffing mobilizes the peripheral secretions. which are then coughed up. This sequence of events is repeated until the whole area to be treated is drained as clear as possible. Most patients will clead two or three areas at any one physiotherapy session?

There is increasing evidence that exercise training schemes which improve exercise tolerance and resis tance to fatigue in the respiratory muscles may bel helpful (Keens et al., 1977).

Mucolytic agents. Infection increases sputum viscos sity but the regular use of mucolytics in CF is not of proved value. Some patients can be helped to expectorate their sputum by using hypertonic saline

Bronchodilators. Many patients with CF have bee shown to have increased bronchial liability (Day and Mearns, 1973). About half the patients with CF shove 


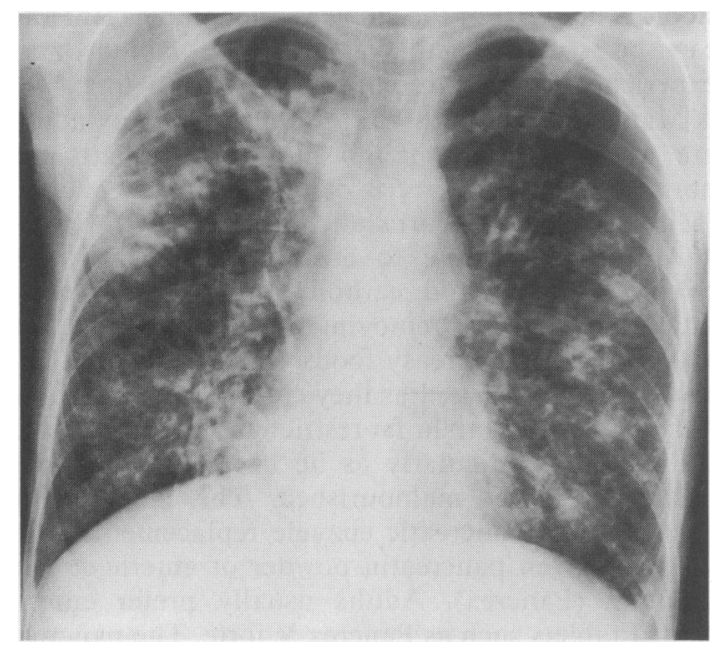

FIG. 1. Chest radiograph of a cystic fibrosis patient showing advanced pulmonary disease (Widespread shadows are seen in both lungs. There is a small pneumothorax on the left).

an increase of over 15\% in PEFR following salbutamol. These patients are advised to use salbutamol by nebulizer or pressurized aerosol before physiotherapy.

Corticosteroids. Instinctively there is a reluctance to use steroids in patients with chronic pulmonary infection. However, the author has used corticosteroids together with appropriate antibiotics in a number of patients with CF with definite benefit. Corticosteroids should be given when there is an acute deterioration of pulmonary symptoms which do not respond to intensive measures, including physiotherapy and antibiotics. They should also be used when the patient shows a slow progressive deterioration in pulmonary function unresponsive to other measures, and in patients who have allergic bronchopulmonary aspergillosis. Patients should be treated with 20-30 $\mathrm{mg}$ of prednisone a day (children $1 \mathrm{mg} / \mathrm{kg} /$ day for a period of 3 weeks and if no improvement occurs the drug should be stopped. If improvement occurs the dose should be reduced to the minimum level needed to maintain the improvement.

\section{Complications}

Cor pulmonale. Patients who develop cor pulmonale will benefit from oxygen during the acute phase together with diuretics and potassium supplements. Digoxin is rarely, if ever, helpful.

Atelectasis. Either lobar or segmental is an unusual complication but may occur in about $5 \%$ of patients (Stern et al., 1978). Treatment is by intensive physiotherapy and antibiotics. If aspergillus sensitivity is involved then steroids are essential. There is no definite evidence that bronchial lavage produces sustained improvement.

Allergic bronchopulmonary aspergillosis. This is reported in CF (Mearns, Young and Batten, 1965; Brueton et al., 1980). The patients have an exacerbation of symptoms together with transient pulmonary shadows and a blood eosinophilia. They have an immediate positive skin test to $A$. fumigatus and usually serum precipitins. The response to steroids is usually marked.

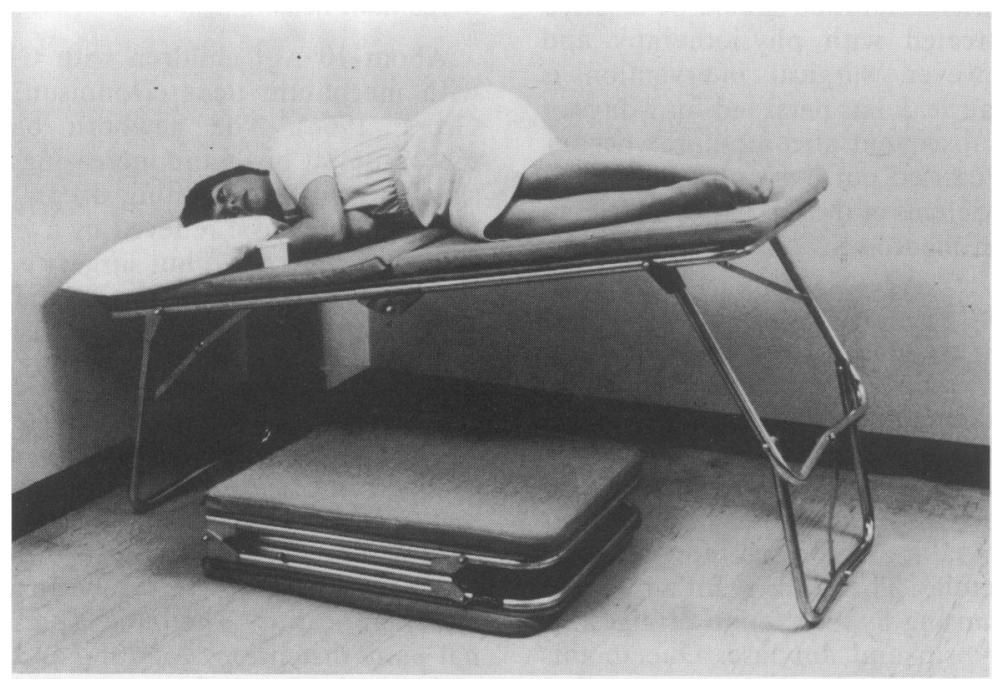

FIG. 2. A small portable tipping bed suitable for use by patients with cystic fibrosis 
Haemoptysis. This is relatively uncommon in young children but may occur in as many as $60 \%$ of older patients. It is usually mild and needs no treatment apart from reassurance. If the haemoptysis is associated with an acute exacerbation of infection antibiotic therapy should be reviewed. About $7 \%$ of older patients, however, have massive and even lifethreatening haemoptysis. Vitamin $\mathrm{K}$ should be given at once especially to those with liver disease and blood cross-matched. Appropriate antibiotics and gentle physiotherapy should be performed. If physiotherapy is not performed because of fear of exacerbating the haemoptysis, sputum retention and respiratory failure occur. If intervention is unavoidable bronchial artery ligation or lobectomy involves a thoracotomy in a patient with advanced pulmonary disease. Bronchial artery occlusion using gelatin foam is an alternative treatment favoured by the author (Fairfax et al., 1980). In expert hands, this treatment can often be dramatically successful.

Spontaneous pneumothorax. In CF this is relatively uncommon in childhood, but with increasing age the incidence increases. In a group of 243 adolescents and adult patients with a mean age of $24 \cdot 2$ years, 46 suffered one or more episodes of spontaneous pneumothorax (Penketh et al., 1983). The reason for the high incidence of spontaneous pneumothorax in these patients is uncertain, but abnormal pleural cells have been reported. The patient may be asymptomatic but if the pneumothorax is of any size there will be complaints of chest pain and breathlessness. The rate of recurrence of the pneumothorax and persistence of air leaks are high. For small asymptomatic pneumothoraces the treatment should be conservative. For a first episode of a symptomatic pneumothorax an intercostal tube should be inserted and the patient treated with physiotherapy and chemotherapy. However, surgical intervention is indicated when an air leak has persisted for 7 days or when a second or subsequent pneumothorax occurs. Surgery should be carried out by a surgeon who is familiar with the problems of the CF patient. He may perform an abrasion pleurodesis or a pleurectomy.

\section{The alimentary tract}

\section{Pancreatic malabsorption}

About $85 \%$ of patients with CF have steatorrhoea (Shwachman, 1975). The primary defect is thought to be an abnormality in electrolyte and bicarbonate secretion in the pancreatic ductules leading to precipitation of calcium salts and protein and ultimate occlusion of the ductules. This leads to inflammation and later fibrosis, causing hyposecretion of digestive enzymes, lipase, trypsin and amylase. Due to this lack of pancreatic enzymes the patient passes frequent bulky, pale, offensive and semi-formed stools. The smell of the stools is often unpleasant anæ can be socially embarrassing. The patient ma experience abdominal discomfort and bloating.

Many children with CF are thin and many adults are underweight, although most patients attain $\overline{\vec{\beta}}$ normal height. Puberty is delayed in many patients (Mitchell-Heggs, Mearns and Batten, 1976; Mearn है 1983). It is essential to ensure a high intake of calories, protein and carbohydrates. Excessive fa intake is avoided by removing visible fat on meat an avoiding obvious greasy foods. Polyunsaturated fats should be encouraged as they contain more essentiā fatty acids. A too rigid fat restriction is inadvisable as the patient, particularly as he becomes older, wiff become severely malnourished. The patients are given regular pancreatic enzyme replacement. Chif dren are given pancreatin powder or enteric coategु granules (Pancrex). Adults usually prefer enterie coated tablets such as Pancrex V forte. The pancreas tin preparations should be taken at intervals through out the meal, the average adult needing at least fives tablets per meal. Small snacks between meals require a lower dose of tablets. In a few patients these measures do not satisfactorily control the steator rhoea. It is thought that this is because their stomach are very acid and so destroy the pancreatic enzymes? In these patients it may be helpful to give adyltit cimetidine 30-45 min before each main meal. Whem cimetidine is used an encapsulated powder formuta:tion of enzymes, such as Pancrex V, should be givew as there is no longer any need for enteric coating Additional supplements of fat soluble vitaming should be given and many clinicians give additionat vitamins $\mathbf{E}$ and $\mathrm{K}$.

\section{Meconium ileus}

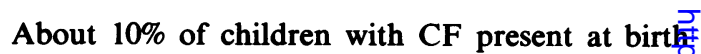
with meconium ileus (Donnison, Shwachman and: Gross, 1966). The newborn baby fails to pass meconium at birth and increasing abdominal distent: sion and bilious vomiting occur. In some cases the obstruction can be relieved by a gastrograffin enema (Wagget et al., 1970) but surgery is usually necessary involving resection of part of the small bowel witb end-to-side anastomosis and a distal ileostomy.

\section{Meconium ileus equivalent}

The term meconium ileus equivalent (MIE) is used to describe a syndrome of small intestinal obstruction seen in older children and adults with CF (Mullins Talamo and di Sant'Agnese, 1965; Hunton, Long and Tsumagari, 1966). MIE can be an acute life-threaten ing complication. The patient presents with abdomi nal pain, distension, vomiting and constipation. The abdominal X-ray shows small bowel obstructiono (Fig. 3). Surgery is best avoided in this conditio 
whenever possible and treatment should be rehydration with an intravenous infusion and nasogastric suction. $\mathrm{N}$-acetylcysteine should be given orally and by enema (Hodson, Mearns and Batten, 1976).

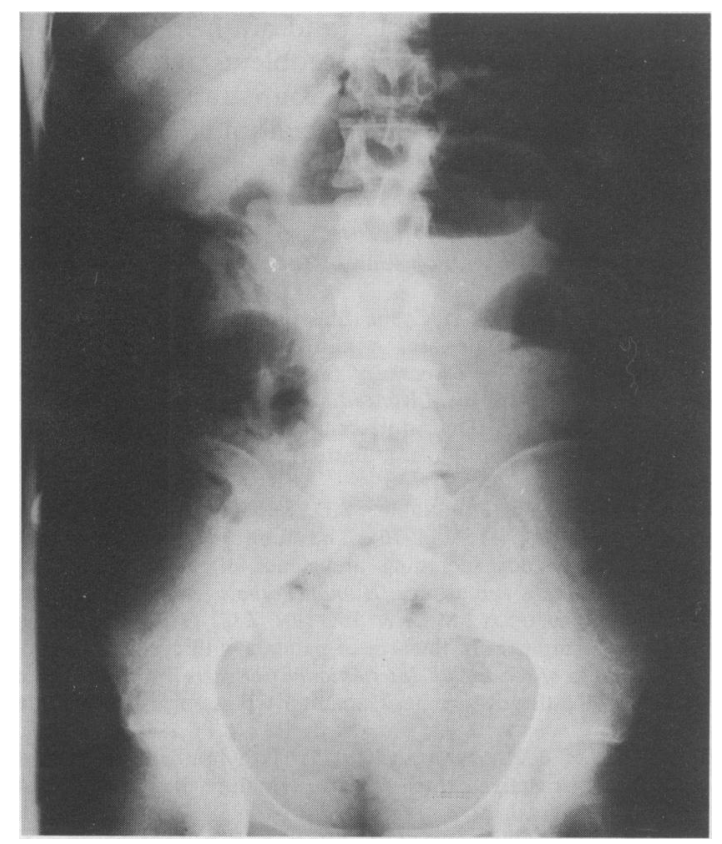

FIG. 3. Abdominal radiograph of an adult with meconium ileus equivalent showing small bowel obstruction.

In many patients a recurring form of sub-acute obstruction causing colicky abdominal pain occurs. Masses may be palpable in the right iliac fossa. These attacks are often preceded by an unusually large or fatty meal or omission of pancreatin. Chronic MIE is best prevented by attention to diet, dose of pancreatin and using cimetidine if necessary.

\section{Rectal prolapse}

Rectal prolapse occurs in about $10 \%$ of young children with CF and may occasionally be the presenting feature. It usually responds satisfactorily to appropriate dietary management.

\section{Acute pancreatitis}

This is a rare complication of CF.

\section{Intussusception}

Intussusception is not uncommon in infants with CF and may occur in older children. A barium enema may allow hydrostatic reduction; when this fails surgery is required.

\section{Duodenal ulcers}

This has been reported in young patients with CF at an age when the condition would otherwise be rare (Park and Grand, 1981).

\section{The liver and biliary system}

The following hepato-biliary disorders may occur in CF (Psacharopoulos and Mowat, 1983): prolonged conjugated hyper-bilirubinaemia in infancy; massive hepatic steatosis in infancy; cirrhosis which may cause alimentary bleeding from portal hypertension, or massive splenic enlargement with splenic pain or hypersplenism; gallstones and bile duct obstruction. Focal biliary cirrhosis is the characteristic lesion found in the liver. The underlying pathological cause is believed to be the accumulation in intrahepatic bile ducts of amorphous eosinophilic PAS positive material. This material blocks the hepatic bile ducts and causes in the portal tracts initially oedema, and then inflammation and chronic fibrosis. Biliary cirrhosis has been found in infants at post-mortem and the incidence rises in older patients. Isenberg et al. (1976) reported cirrhosis in $37 \%$ of 56 patients, 6 months to 21 years, submitted to liver biopsy.

\section{Social and psychological features}

The diagnosis of CF in a child has profound implications for the parents. It is essential that the paediatrician handles the parents with great tact as they gradually learn about this disease and its genetic implications. As children survive into adolescence they often go through a 'rebellious phase', when they resent mother and father helping them with physiotherapy. They begin to resent the fact that unlike other children they have to take pancreatic enzymes, antibiotics and regularly visit hospital. It is during this stage that they are usually transferred from the paediatrician to the thoracic physician.

The adult patient is best cared for in a specialized unit where there is expertise in the problems of caring for an adolescent and adult with CF. In addition to medical and nursing staff, physiotherapists, dietitians, social workers, pharmacists, thoracic, ENT and obstetric surgeons with a special interest in this condition should be readily available for consultation.

The transfer from the paediatrician to the adult $\mathrm{CF}$ unit needs to be handled with great tact by all involved so that the confidence of the young person in his ability to live with his disease is increased. It is at this stage that it is useful to teach the patient the forced expiration technique of physiotherapy, so that he can become independent of parental help during treatment sessions. It is sometimes advantageous to admit the adolescent to hospital for a week or so, to 
enable him to become fully conversant with all the details of his disease and management. He must learn to take full responsibility for his own health care. Whenever possible, children with CF should go to normal schools and should be encouraged to attain as high an educational standard as possible. Many young people now go to college and university. It is important that the social worker attached to the Cystic Fibrosis Unit is interested in the young persons' career aspirations early in adolescence so that patients can be guided into suitable jobs.

There are now many patients with CF reaching adult life, some are married and a few have children (Batten, 1983b). The vast majority of males with CF are infertile, but the females are fertile. The majority of female patients, however, have lung function which would make it inadvisable for them to have children. Even if they survived the pregnancy they would be too breathless to care for an active toddler. In these cases adequate contraceptive advice must be given. If their lung function is good and they and their husband understand the risks they are taking and they choose to go ahead with pregnancy, then specialized care is required. The obstetrician must work closely with the thoracic physician. The patient is usually admitted to hospital a few weeks before delivery so she can have intensive chest physiotherapy. It is also important to continue this immediately after delivery.

Even with the best currently available medical treatment, CF is a serious disease, and one is, on occasions, faced with the baby, toddler, child, or young adult who is dying. This is usually from respiratory failure. There comes a time when aggressive treatment is not indicated and all efforts must be transferred to symptom relief and making sure the young person is comfortable (Norman and Hodson, 1983). Some patients may die at home, others in hospital. It is essential that they are cared for by those they know, and that attention is paid to their very natural anxieties as well as to their physical problems.

\section{Prognosis}

The Cystic Fibrosis Foundation (1978) reports 50\% survival to 21 years in the United States and 22 years in Canada. The Brompton reported a probability of survival to 20 years of 0.85 , to 25 years 0.63 , and to 30 years 0.46 (Batten, 1983b). This is almost identical to data reported by Allan and Phelan (1980) from Australia. A marked improvement in survival of CF patients is seen when the survival of patients treated in a CF centre is compared to that of patients treated exclusively in other departments (Warwick, 1982).

\section{Conclusions}

The prognosis for cystic fibrosis has change dramatically since it was first described in 1938. The diagnosis is now no longer a sentence of death within: 1 or 2 years and patients have a reasonable chance o surviving into adolescence and adult life. Howeve 6 these older patients have problems which do not occur in the paediatric age group, and it is essentia that they are cared for in special units.

\section{References}

Allan, J.L. \& Phelan, P.D. (1980) Cystic fibrosis: Survival to adu $\vec{\Phi}$ life: ability to live with disability. Medical Journal of Australia, 600.

ANDERSON, D.H. (1938) Cystic fibrosis of the pancreas and iR relation to celiac disease. A clinical and pathological stud American Journal of Diseases of Children, 56, 344.

BAtTEN, J.C. (1983a) In: Advanced Medicine. Pitman, London.

BATTEN, J.C. (1983b) The Adolescent and Adult. In: Cystic Fibrosis (Eds. Hodson, Norman and Batten), Ch. 12. Bailliere TindaB, London.

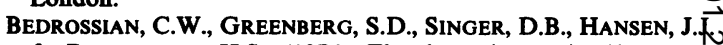
\& ROSENBERG, H.S. (1976) The lung in cystic fibrosis. A quantitative study including prevalence of pathologic findings among different age groups. Human Pathology, 7, 195.

Beldon, I., Hodson, M.E. \& BATTEN, J.C. (1980) Circulating immune complexes in the sera of patients with cystic fibrosis. If Proceedings of the Eighth International Congress in Cystic Fibrosiag (Ed. J. M. Sturgess), p. 3a. Canadian CF Association, Toront艿 Canada.

BROCK, D.J.H. \& HAYWARD, C. (1979) Methylumbelliferylguaffdio nobenzoate reactive proteases and premature diagnosis of cost fibrosis. Lancet, i, 1245.

BRUETON, M.J., ORMEROD, L.P., SHAH, K.J. \& ANDERSON, (1980) Allergic bronchopulmonary aspergillosis complicatin cystic fibrosis in childhood. Archives of Diseases in Childhood, 5 2ू 348.

Crossley, J.R., Elliott, R.B. \& SMith, P.A. (1979) Dried-bloo spot screening for cystic fibrosis in the newborn. Lancet, i, 472. CYSTIC FIBRosis Foundation: Report of the Patient Registry 1978.

Dandona, P., Hodson, M., Bell, J., Ramdial, L. \& Batten, J.C (1979) Serum immunoreactive-trypsin concentrations in cystio fibrosis. Lancet, i, 1032.

DAY, G. \& MEARNS, M.B. (1973) Bronchial liability in cystic fibrosis. Archives of Disease in Childhood, 48, 355.

Donnison, A.B., Shwachman, H. \& Gross, R.E. (1966) A review of 164 children with meconium ileus seen at the Children Hospital Medical Center, Boston. Pediatrics, $37,833$.

DREILING, D.A. \& JANOWITZ, H.D. (1962) The exocrine pancreas. normal and abnormal functions. (Ed. A.V.S. de Reuck and M.D? Cameron) Ciba Foundation, Churchill, London.

EfThimiou, J., Hodson, MARgaret E., TAYLOR, P., TAYLOR, A.Go \& BATTEN, J.C. (1984) The importance of viruses and legionella pneumophila in the respiratory exacerbations of young adul with cystic fibrosis. Thorax, (in press).

Fairfax, A.J., Ball, J., BatTen, J.C. \& Heard, B.E. (1980) AN pathological study following bronchial artery embolisation fơ haemoptysis in cystic fibrosis. British Journal of Diseases of thre Chest, 74, 345.

FANCONI, G., Uehlinger, R.E. \& KNAUER, C. (1936) Daș Coelroksyndrom bei Angeborener zystisher pankreas fibromatosए und bronchiektasiem. Weiner medizinische Wochenschrift, 86, 753

GiBSON, L.E. \& COOKE, R.E. (1959) A test for concentration of electrolytes in sweat in cystic fibrosis of the pancreas utilizing pilocarpine by iontophoresis. Pediatrics, 23, 545.

HoDSON, M.E. (1980) Immunological abnormalities in cystic fibro-0 sis: chicken or egg. Thorax, 35, 801 . 
Hodson, M.E. \& BATTEN, J.C. (1981) Azlocillin compared with carbenicillin and tobramycin compared with Gentamicin in the treatment of Pseudomonas aeruginosa infection in patients with cystic fibrosis. Mongr. Paediatr. Karger, Basel, 14, 124.

Hodson, M.E., Beldon, I., Power, R., Duncan, F.R., Bamber, M. \& BATTEN, J.C. (1983) Sweat tests to diagnose cystic fibrosis in adults. British Medical Journal, 286, 1381.

Hodson, M.E. \& GASkell, D.V. (1983) Physiotherapy, In: Cystic Fibrosis. (Ed. Hodson, Norman and Batten), Ch. 13. Bailliere Tindall, London.

Hodson, M., Mearns, M. \& Batten, J. (1976) Meconium ileus equivalent in adults with cystic fibrosis of pancreas: a report of six cases. British Medical Journal, 21, 790.

Hodson, M.E., Penketh, A.R.L. \& Batten, J.C. (1981) Aerosol carbenicillin and gentamicin treatment of Pseudomonas aeruginosa infection in patients with cystic fibrosis. Lancet, ii, 1137.

HodsON, M.E. \& TURNER-WARWICK, M. (1981) Autoantibodies in cystic fibrosis. Clinical Allergy, 11, 565.

HODSON, M.E. \& WARNER, J.O. (1983) Immunology In: Cystic Fibrosis. (Ed. Hodson, Norman and Batten), Ch. 5. Bailliere Tindall, London.

Hodson, M.E., WingField, H.J. \& BATTEN, J.C. (1983) Tobramycin and carbenicillin compared with gentamicin and carbenicillin in the treatment of infection with Pseudomonas aeruginosa in adult patients with cystic fibrosis. British Journal of Diseases of the Chest, 77, 71.

HunTON, D.B., LONG, W.K. \& Tsumagari, H.Y. (1966) Meconium ileus equivalent: an adult complication of fibrocystic disease. Gastroenterology, 50, 99.

ISENBERG, J.N., L'HeUReUX, P.R., WARWICK, W.J. \& SHARP, H.L. (1976) Clinical observations of the biliary system in cystic fibrosis. American Journal of Gastroenterology, 65, 134.

KEENS, T.G., KRASTINS, I.R.B., WANNAMAKER, E.M., LEVISON, H., CROZIER, D.N. \& BRYAN, A.C. (1977) Ventilatory muscle endurance training in normal subjects and patients with cystic fibrosis. American Review of Respiratory Diseases, 116, 853.

KUZEMKo, J.A. \& HeEleY, A.F. (1983) Diagnostic methods and screening. In: Cystic Fibrosis. (Ed. Hodson, Norman and Batten), Ch. 2. Bailliere Tindall, London.

Levison, H. \& TABACHNIK, E. (1983) Pulmonary physiology. In: Cystic Fibrosis. (Ed. Hodson, Norman and Batten), Ch. 4. Bailliere Tindall, London.

MCCARTHY, M., RouRK, M.H. \& SPORK, A. (1980) Bacteraemia in patients with cystic fibrosis. Clinical Pediatrics, 19, 746.

McFarlane, H., Holzel, A. Brenchley, P. Allan, J.D., WALLWORK, J.C., SiNGER, B.E. \& WORSLEY, B. (1975) Immune complexes in cystic fibrosis. British Medical Journal, 1, 423.

MCKENDRICK, T. (1962) Sweat sodium levels in normal subjects, in fibrocystic patients and their relatives, and in chronic bronchitic patients. Lancet, i, 183.

Matthews, W.J., JR, Williams, M., Oliphint, B., Geha, R. \& ColTEN, H.R. (1980) Hypogammaglobulinaemia in patients with cystic fibrosis. New England Journal of Medicine, 302, 245.

MEARNS, M.B. (1983) Growth and Development. In: Cystic Fibrosis. (Ed. Hodson, Norman and Batten), Ch. 10. Bailliere Tindall, London.

Mearns, M.B., Longbottom, J. \& BATten, J.C. (1967) Precipitating antibodies to Aspergillus fumigatus in cystic fibrosis. Lancet, $\mathbf{i}$, 538 .

MearnS, M.B., Young, W. \& BatTen, J.C. (1965) Transient pulmonary infiltrations in cystic fibrosis due to allergic aspergillosis. Thorax, 20, 385 .

Mitchell-Heggs, P., Mearns, M. \& Batten, J.C. (1976) Cystic fibrosis in adolescents and adults. Quarterly Journal of Medicine, 45, 479.

Mullins, F., Talamo, R. \& di Sant'Agnese, P. (1965) Late intestinal complications of cystic fibrosis. Journal of the American Medical Association, 192, 741.

Nadler, H.L., Rembelski, P. \& Mesirow, K.H. (1981) Prenatal diagnosis of cystic fibrosis. Lancet, ii, 1226.

NORMAN, A.P. \& HodSON, M.E. (1983) Emotional and social aspects of treatment in cystic fibrosis. In: Cystic Fibrosis. (Ed. Hodson, Norman and Batten), Ch. 14. Bailliere Tindall, London

PARK, R.W. \& GRAND, R.J. (1981) Gastrointestinal manifestations of cystic fibrosis: a review. Gastroenterology, 81, 1143.

Penketh, A.R.L., Hodson, M.E. \& BatTen, J.C. (1982b) Ticarcillin compared with carbenicillin in the treatment of exacerbations of bronchopulmonary infection due to Pseudomonas aeruginosa in cystic fibrosis. Proceedings of 11th Annual Meeting European Working Group in Cystic Fibrosis. p. 250. Published Belgian C.F. Association.

Penketh, A.R.L., Knight, R.K., Hodson, M.E. \& Batten, J.C. (1982a) The management of pneumothorax in adults with cystic fibrosis. Thorax, 37, 850 .

PrioR, J. \& CRAWFORD, A.D. (1980) Systemic amyloidosis complicating cystic fibrosis. British Journal of Diseases of the Chest, 74, 84.

Pryor, J.A, Webber, B.A., Hodson, M.E. \& BatTen, J.C. (1979) Evaluation of the Forced Expiration Technique as an adjunct to postural drainage in treatment of cystic fibrosis. British Medical Journal, 2, 417.

Psacharopoulos, H.T. \& Mowat, A.P. (1983) The Liver and Biliary System. In: Cystic Fibrosis. (Eds. Hodson, Norman and Batten), Ch. 9. Bailliere Tindall, London.

RaEbURN, J.A. (1983) Genetics and Genetic Counselling. In: Cystic Fibrosis. (Eds. Hodson, Norman and Batten), Ch. 1. Bailliere Tindall, London.

RaO, G.J.S., PlatT, N.W. \& Nadler, H.L. (1978) Reaction of 4 methyl umbelliferylguanrdino benzoateas with proteases in plasma of patients with cystic fibrosis. Enzyme, 23, 314.

SACHER, M., KoBSA, A. \& SHMERLING, D.H. (1978) PABA screening test for exocrine pancreatic function in infants and children. Archives of Disease in Childhood, 53, 639.

Sant'Agnese, P.A. Di, Darling, R.C., Perera, G.A. \& Shea, E. (1953) Abnormal electrolyte composition of sweat in cystic fibrosis of the pancrease; clinical significance and relationship to the disease. Pediatrics, 12, 549.

SANT'Agnese, P.A. DI \& Davis, P.B. (1976) Research in cystic fibrosis. New England Journal of Medicine, 295, 481, 534, 597.

ShwaChmaN, H. (1975) Gastrointestinal manifestations of cystic fibrosis. Pediatric Clinics of North America, 22, 787.

Shwachman, H., Mahmoodian, A. \& NefF, R.K. (1981) The sweat test: sodium and chloride values. Journal of Pediatrics, 98, 576.

STERN, R.C., Boat, T.F., ORenstein, D.M., Wood, R.E., MatTHEWS, L.W. \& DoERSHUK, C.F. (1978) Treatment and prognosis of lobar and segmental atelectasis in cystic fibrosis. American Reviews of Respiratory Diseases, 118, 821.

WAGGET, J., Johnson, D.G., BoRns, P. \& Bishop, H.C. (1970) The nonoperative treatment of meconium ileus by Gastrografin enema. Journal of Pediatrics, 77, 407.

WALlWORK, J.C., BRENCHLEY, P. \& MACARThY, J. et al. (1974) Some aspects of immunity in patients with cystic fibrosis. Clinical and Experimental Immunology, 18, 303.

Warren, C.P.W., TaI, E., Batten, J.C., Hutchcroft, B.J. \& PEPYS, J. (1975) Cystic fibrosis: immunological reactions to Aspergillus fumigatus and common allergens. Clinical Allergy, 5,

Warwick, W.J. (1982) Prognosis for survival with cystic fibrosis: The effects of early diagnosis and cystic fibrosis center care. Acta Paediatrica Scandinavica, 301, (Suppl.) 27.

Williamson, R., Crampton, J. \& Clarke, B. (1983) Research perspectives: the basic defect in cystic fibrosis. In: Cystic Fibrosis. (Eds. Hodson, Norman and Batten), Ch. 15. Bailliere Tindall, London.

WILSON, G.B. (1980) Monospecific antisera, hydridoma antibodies and immunoassays for cystic fibrosis patients. Lancet, ii, 313.

WILSON, G.B. \& FUDENBERG, H.H. (1978) Is cystic fibrosis protein a diagnostic marker for individuals who harbour the defective gene? Paediatric Research, 12, 801.

WOOD, R.E., BOAT, T.F. \& DOERSHUK, C.F. (1976) Cystic fibrosis American Review of Respiratory Diseases, 113, 833. 